\title{
Article
}

\section{Prospective memory functioning among ecstasy/polydrug users: evidence from the Cambridge Prospective Memory Test (CAMPROMPT)}

Hadjiefthyvoulou, Florentia, Fisk, John, Montgomery, Catharine and Bridges, Nikola Jane

Available at http://clok.uclan.ac.uk/2169/

Hadjiefthyvoulou, Florentia, Fisk, John ORCID: 0000-0002-2981-0870, Montgomery, Catharine and Bridges, Nikola Jane ORCID: 0000-0002-8207-

7241 (2011) Prospective memory functioning among ecstasy/polydrug users: evidence from the Cambridge Prospective Memory Test (CAMPROMPT). Psychopharmacology, 215 (4). pp. 761-774. ISSN 0033-3158

It is advisable to refer to the publisher's version if you intend to cite from the work. http://dx.doi.org/10.1007/s00213-011-2174-y

For more information about UCLan's research in this area go to http://www.uclan.ac.uk/researchgroups/ and search for < name of research Group>.

For information about Research generally at UCLan please go to http://www.uclan.ac.uk/research/

All outputs in CLoK are protected by Intellectual Property Rights law, including Copyright law. Copyright, IPR and Moral Rights for the works on this site are retained by the individual authors and/or other copyright owners. Terms and conditions for use of this material are defined in the policies page. 
Prospective Memory Functioning among Ecstasy/Polydrug users: Evidence from the Cambridge Prospective Memory Test (CAMPROMPT).

Florentia Hadjiefthyvoulou ${ }^{1}$, John E. Fisk ${ }^{1}$, Catharine Montgomery ${ }^{2}$, Nikola Bridges ${ }^{1}$

1 School of Psychology, University of Central Lancashire

2. School of Natural Sciences \& Psychology, Liverpool John Moores University

Running head: CAMPROMPT deficits among illicit drug users.

\section{Corresponding author:}

Professor John E Fisk, PhD

School of Psychology

University of Central Lancashire

Preston PR1 2HE

United Kingdom

Tel 44 (0) 1772894465

Fax 44 (0) 1772892925

e-mail: jfisk@uclan.ac.uk

\section{Acknowledgements}

The authors declare that, except for income received from their primary employers, this research received no specific grant from any funding agency in the public, commercial, or not-for-profit sectors. The authors are not aware of any conflict of interest and do not have any financial interest in this piece of research. 


\begin{abstract}
Rationale: Prospective memory (PM) deficits in recreational drug users have been documented in recent years. However the assessment of PM has largely been restricted to self report measures that fail to capture the distinction between event based and time based PM. The aim of the present study is to address this limitation.
\end{abstract}

Objectives: Extending our previous research we augmented the range laboratory measures of PM by employing the CAMPROMPT test battery to investigate the impact of illicit drug use on prospective remembering in a sample of cannabis only, ecstasy/polydrug and non users of illicit drugs, separating event and time based PM performance. We also administered measures of executive function and retrospective memory in order to establish whether ecstasy/polydrug deficits in PM were mediated by group differences in these processes.

Results: Ecstasy/polydrug users performed significantly worse on both event and time based prospective memory tasks in comparison to both cannabis only and non user groups. Furthermore, it was found that across the whole sample, better retrospective memory and executive functioning was associated with superior PM performance. Nevertheless, this association did not mediate the drug-related effects that were observed. Consistent with our previous study, recreational use of cocaine was linked to PM deficits.

Conclusions: PM deficits have again been found among ecstasy/polydrug users which appear to be unrelated to group differences in executive function and retrospective memory. However, the possibility that these are attributable to cocaine use cannot be excluded. 
Prospective memory (PM) involves remembering to execute a particular behaviour at some future point in time which may be in the short or long term, for example remembering to turn off the lights when leaving a room or remembering to attend a meeting, meet a friend or pass on a message. Self report measures of this construct have been developed (e.g., Crawford et al., 2005; Hannon et al., 1995) and in previous research from our laboratory, Fisk and co-workers have demonstrated apparent impairments on these measures among ecstasy/polydrug users (Montgomery \& Fisk, 2007) and cannabis only users (Fisk \& Montgomery, 2008). Other researchers have also reported deficits on self report PM measures among users of illicit drugs (Heffernan et al., 2001a; 2001b; Rodgers et al., 2001; 2003) and studies from our own laboratory and elsewhere have revealed deficits among illicit drug users in laboratory measures of PM (Hadjiefthyvoulou et al., in press; Rendell et al., 2007a; Rendell et al., 2009).

Unsurprisingly, given their role in supporting memory functions in general, evidence suggests that PM is dependent on medial temporal-hippocampal processes. For example, in a clinical group with medial temporal sclerosis, Adda et al. (2008) found that PM performance was impaired and that among those with left hemisphere lesions the degree of impairment was correlated with that in delayed (7 day) verbal recall on the Rey Auditory Verbal Learning Task (RAVLT). Leitz et al. (2009) found that PM performance was significantly correlated with episodic memory recall following acute administration of alcohol. In another recent study utilising magnetoencephalography, Martin et al. (2007) found that that the hippocampal region was activated longer during both retrospective and prospective memory tasks relative to a control condition. Interestingly other regions were also differentially implicated, since compared to the retrospective and control tasks, the PM task was associated with earlier onset of activation in the posterior parietal lobe. In an animal study by Goto and Grace (2008) in which rats searched for food rewards in a radial maze, prospective and retrospective memory elements of PM were explored. The results suggested that the retrospective aspect although requiring hippocampal input also recruits PFC resources before the prospective component can be activated. Furthermore the dopaminergic system appeared to differentially support this process with the D1 receptor apparently supporting the former aspect and the D2 receptor the latter prospective component. Since ecstasy impacts both serotonergic and dopaminergic processes, this raises the possibility that disruption of dopaminergic processes might be responsible for the PM deficits that have been observed in human drug users.

Aside from its reliance on medial temporal structures, PM is known to utilise prefrontal executive processes including the working memory system. Neuroimaging studies 
have revealed the involvement of the frontopolar cortex (Brodmann area 10) and neighbouring prefrontal areas during the performance of PM tasks (Okuda et al., 2007). Other research utilising dual task methodology (Marsh \& Hicks, 1998) cognitive ageing paradigms (McDaniel et al., 1999) and Parkinson’s related deficits (Kliegel et al., 2005) has also linked PM functioning to prefrontal lobe capacity.

It is worthy of note that prospective memory functions may be defined as either eventbased or time-based. For example, some predefined external event may trigger the retrieval of the intention to act, or alternatively the trigger may be the elapse of a given period of time. There is evidence to suggest that the two classes utilise neural processes that are at least in part separable. For example, Burgess et al., (2003) and Gilbert et al., (2005) have shown that event-based tasks utilise the frontopolar cortex, including Brodmann area 10 (BA10). Similar findings were reported by Fleming et al. (2008) in patients with frontally based traumatic brain injury (TBI), particularly in relation to event-based PM. More recently PET scanning has revealed that while the left superior frontal gyrus was involved in both types of tasks, different areas within this structure were found to be activated. Furthermore, in addition to the frontopolar cortex, the time-based tasks also activated more diverse regions including anterior medial frontal regions, the right superior frontal gyrus and the anterior cingulate (Okuda et al., 2007). Given the clear dependence of PM on medial temporal/hippocampal processes and on the PFC, it is also clearly of relevance that ecstasy/polydrug related deficits have been observed on tasks supported by these structures, including aspects of executive functioning (see Murphy et al., 2009 for a review). It would therefore be of value to determine whether or not the drug-related deficits in medial temporal processes and in PFC functions are responsible for the ecstasy/polydrug related deficits that have been observed in PM.

While a number of researchers have used self-report measures to investigate PM deficits among illicit drug users (Heffernan et al., 2001a; 2001b; Montgomery and Fisk, 2007; Rodgers et al., 2001; 2003), to date relatively few studies in this area have used laboratory tests of prospective memory. McHale and Hunt (2008) administered two simple laboratory tests: remembering to press a timer 10 minutes after being instructed to do so and remembering to post an envelope back to the experimenter two days after the test session. Cannabis users were found to be impaired on both of these measures. A popular recent addition to laboratory measures of PM is the 'virtual week' paradigm. This PM test is a board game completed in the laboratory in which the participant is required to execute previously learned tasks at specified points as they progress around the board at specific times or in 
conjunction with specific events. This measure has featured in a number of studies. For example, deficits were observed on this measure among currently abstinent ecstasy users including those who used infrequently (Rendell et al., 2007a). Long term abstinent methamphetamine users were also found to be impaired on the measure relative to a drug naive control group (Rendell et al., 2009). Furthermore, impairments were also evident in measures of verbal learning and delayed recall (RAVLT), forward and backward digit span, and the Hayling sentence completion task (believed to load on the inhibitory executive process). The extent of the methamphetamine-related effect in PM was found to covary substantially with the degree of impairment on the Hayling task (Rendell et al., 2009). In other research utilising the virtual week, Leitz et al. (2009) demonstrated that performance was impaired following the acute administration of alcohol. However, in a subsequent study, the deficit was eliminated when individuals were instructed simulate the required actions at the time of encoding (by imaging the full sensory aspects of the context in which the action was to be completed; Paraskevaides et al., 2010). The measure has also been used to investigate the basis of PM deficits in individuals with mild cognitive impairment and dementia (Thompson et al., 2010), multiple sclerosis (Rendell et al., 2007b) and schizophrenia (Henry et al., 2007).

While the virtual week paradigm has its merits, before the PM element can be completed, it is necessary to learn each of the ten particular responses that is paired with specific locations on the board and select the appropriate response from among the set of available alternatives each time a PM action is triggered. This is made easier by the fact that some responses are common to different tasks. Thus However, the test has clearly has an substantial associative learning component and Montgomery et al. (2005) have demonstrated that ecstasy users are impaired on paired associative learning. Thus it is possible that some of the deficits evident on the virtual week might be attributable to this aspect rather than the PM components. In this regardThat said, it is worthy of note that some-just over half of the virtual week PM sub-tasks are regular and more repetitive in nature and thus more readily learned. It is the while others areremaining more irregular tasks with that have a more substantial learning requirement. Interestingly ecstasy users performed worse on these irregular virtual week tasks recording $65 \%$ of the level of correct responses achieved by nonusers while for regular tasks the percentage was 83\% (computed from Table 2; Rendell et al., 2007a). This suggests that performance is indeed adversely affected by the learning component. Nonetheless it must be acknowledged that there was no statistically significant interaction between user group and task type with users demonstrating a significant deficit overall. Thus 
while group differences in learning may partially account for the Thus the role of leaming in accounting for the virtual week results remains uncleathe outcomes obtained are nonetheless consistent with an ecstasy-related PM deficit..

In our previous study (Hadjiefthyvoulou et al., in press) in order to minimise the learning requirement we used a small number of more simple PM tasks, for each of which only a single stimulus-response paring needed to be learned. We also used the Rivermead Behavioural Memory Test (RBMT; Wilson et al., 1999) battery which includes three separate PM tasks. In our study, only one of the three RBMT PM measures produced statistically significant ecstasy/polydrug related deficits. However, the RBMT has been criticised as lacking the sensitivity to detect memory problems in non clinical populations (Spooner \& Pachana, 2006). Thus it may be that the test was not appropriate for the university based sample of recreational drug users which featured in our previous study. A more up-to-date test battery that is sensitive to individual differences both within clinical and normal populations is the Cambridge Prospective Memory Test (CAMPROMPT; Fleming et al., 2008; Groot et al., 2002; Wilson et al., 2005). The purpose of the present study is to confirm and extend our previous findings utilising the more sensitive CAMPROMPT measure. At the same time we will take measures of executive functioning and retrospective memory in order to establish the extent to which any ecstasy/polydrug deficits in PM that are uncovered are mediated by deficits in those memory and executive functions that are known to underpin PM processes. This aspect was not addressed in our previous study. A further innovation in the present study is the inclusion of a cannabis-only control group (i.e., individuals whose illicit drug use is restricted to cannabis). Using self-report measures we (Fisk \& Montgomery, 2008) have previously documented PM deficits among cannabis only users (relative to nonusers of illicit drugs). However we have not previously assessed a cannabis-only user group on laboratory measures of PM and not in relation to ecstasy/polydrug users. It is expected that both illicit drug using groups will perform worse than nonusers of illicit drugs on the CAMPROMPT measures. No prediction is made in relation to PM differences between the two illicit drug using groups.

\section{Method}

\section{Design and Analytical Strategy}

A between participants design was employed with drug using group with three levels (ecstasy/polydrug, cannabis-only, and nonusers of illicit drugs) as the independent variable. The dependent variables were the CAMPROMPT time and event based PM scores. 
Background variables and the executive and recall measures were also assessed for group differences.

Pearson's correlation coefficients were calculated between the PM measures and respectively the executive and recall measures. Regression analyses were conducted with the PM measures as dependent variables. In each regression, those variables that were significantly correlated with the PM measures and any background measures yielding statistically significant drug-related differences were included as predictors. Since the drug use IV had nominal level of measurement it was not possible to include it directly in the regression. Following the procedure outlined by Tabachnick and Fidell (2007), group differences were incorporated into the regression by constructing two dichotomous variables. In the first, ecstasy/polydrug users were coded as ' 1 ' and all other persons coded as ' 0 ', in the second cannabis-only users were coded as ' 1 ' with all other persons coded as ' 0 '. In this way it was possible to establish whether each group accounted for statistically significant unique variance while controlling for the effects of the other predictors.

Participants.

Twenty-nine ecstasy/polydrug users (12 females), 12 cannabis-only users (7 females), and 18 nonusers of illicit drugs (16 females) took part in this investigation (for demographic details see Table 1). The gender composition differed significantly between the groups with females predominating among the non illicit user group and males among the ecstasy/polydrug users, $\chi 2(\mathrm{~N}=59, \mathrm{DF}=2)=10.40, \mathrm{p}<.01$. Participants were recruited via direct approach to university students and the snowball technique, i.e., word-of-mouth referral (Solowij et al., 1992). All participants were university students attending the University of Central Lancashire (UCLAN) or Liverpool John Moores University (LJMU). Materials

A background drug-use questionnaire that has been previously employed by us (Montgomery et al., 2005) assessed the history of illicit drug use and estimated the total lifetime use, frequency of use, recent consumption, as well the period of abstinence, for each drug (e.g. ecstasy, cannabis, amphetamines, cocaine etc). Fluid intelligence was measured via Raven's Progressive matrices (Raven et al., 1998) and a further questionnaire assessed the participant's age and gender, the number of years of education and their current use of alcohol and cigarettes.

Prospective and retrospective memory questionnaire (PRMQ; Crawford et al., 2005). The PRMQ provides a self report measure of prospective and retrospective memory slips in everyday life. It consists of sixteen items, eight referring to prospective memory failures e.g. 
“Do you decide to do something in a few minutes time and then forget to do it?” and eight concerning retrospective failures e.g. " Do you fail to recognize a place you have visited before?”. Participants were asked to specify how often these things happened to them on a 5point scale” very often, quite often, sometimes, rarely, never. Ratings were subsequently assigned numerical values of 5 (very often) to 1 (never). A total score for each subscale (prospective memory and retrospective memory) was also calculated with minimum score of 8 and maximum score of 40 with higher scores indicative of more memory problems.

Rey Auditory Verbal Learning Test (RAVLT; based on Rey, 1964). The RAVLT is a test developed to evaluate verbal learning and memory. A list (List A) of 15 words was presented to the participant orally, with the aid of an audio recording device, for five consecutive times. At the end of each trial the participant was asked to recall as many words as possible from the list. After the fifth trial, an interference list (List B), also consisting of 15 words was read to the participant after which she/he was asked to recall as many words as possible from the interference list. Immediately following this the participant was again asked to recall the words from list A without hearing it again (trial 6). Next after a 20-minute interval, the participant was asked to remember the words from list A (trial 7) after which a recognition test was administered. For the recognition test a list consisting of the 15 words from list A and 15 distracter words was read to the participant and the individual was asked to indicate whether the word belonged to list A or not. A number of outcome measures were produced, first the total number of words correctly recalled over trials one to five, second a measure of proactive interference (number correct on trial one minus number correct on the interference list), third retroactive interference (number correct on trial five minus number correct on trial six) and fourth, a measure of decay (number correct on trial five minus number correct on trial 7).

Memory compensation questionnaire (MCQ; Dixon, de Frias \& Bäckman,2001). The MCQ is a 44 item self-report measure assessing the variety and number strategies the participant uses to compensate for deficient memory performance. The MCQ is comprised of seven subscales: external (e.g. “Do you use shopping lists when you go shopping?”); internal (e.g. "Do you take your time to go through and reconstruct an event you want to remember?”): time (e.g. “Do you ask people to speak slowly when you want to remember what they are saying?”); reliance (e.g. "When you want to remember an important appointment do you ask somebody else (for example, spouse or friend) to remind you?”); effort (e.g. "Do you put in a lot of effort when you want to remember an important conversation with a person?”); success (e.g. “When you want to remember a newspaper 
article is it important to you to remember it perfectly?”); and change (e.g. "Do you use such aids for memory as notebooks or putting things in certain places more or less often today compared to 5-10 yrs ago?”). Responses for each item are presented on a 5-point scale, with higher scores representing more frequent use of the specified compensatory behavior (1=never, 5=always) with some items being reversely scored.

Behavioral Rating Inventory of Executive Function-Adult Version (BRIEF-A) (Roth et al., 2005). The BRIEF-A is a 75 item measure of executive function. For each item the participant responds on a three point scale: Never, Sometimes and Often. The measure provides indicators of nine aspects of executive functions. These map onto two higher level indices the Behavioral Regulation Index (BRI) and the Metacognitive Index (MI). The BRI refers to the ability of the individual to maintain appropriate regulatory control of their own behavior and emotional responses and is comprised of four sub-scales; Inhibit (e.g. "I tap my fingers or bounce my legs”), Shift ( e.g. "I have trouble changing from one activity to another”), Emotional Control (e.g. "I have angry outbursts”), and Self-Monitor (e.g. "I don't notice when I cause others to feel bad or get mad until is too late”). The MI refers to the individual's ability to systematically solve problems through effective planning and organization. It relates directly to the ability to engage in active problem solving across a variety of contexts and is comprised of five sub-scales; Initiate (e.g. "I need to be reminded to begin a task even when I am willing”),Working Memory (“I have trouble concentrating on tasks (such a chores, reading or work)”), Plan/Organize (e.g. “I get overwhelmed by large tasks”), Task Monitor (e.g. “I make careless errors when completing tasks”), and Organization of Materials (e.g. "I am disorganized”). For both the BRI and the MI higher scores are indicative of more executive dysfunction.

The Cambridge Prospective Memory Test (CAMPROMPT) (Wilson et al., 2005). The CAMPROMPT is a laboratory measure of prospective memory that consists of a total of six prospective memory tasks, three cued by time and three cued by events. Participants were asked to work on some distractor tasks such as word-finder puzzles or a general knowledge quiz for a twenty minute period while they had to remember to perform the prospective memory tasks. The participants were allowed to spontaneously use strategies, such as taking notes, to help them remember. Two of the three time based tasks were cued by a countdown kitchen timer and the participant had to remind the experimenter not to forget his/her mug or keys when there were seven minutes left to the end of the session. In the second task, when the timer showed sixteen minutes the examiner asked the participant to remember that "in seven minutes time” he/she had to stop whichever task was they were on and change to 
another. The third time based task was cued by a clock. The participant was asked at a specific time (e.g. ten past eleven; 5 minutes after the 20 minute session) to remind the examiner to ring the reception/garage. For the event based tasks the participant was asked: 1) to return a book to the examiner when he/she came to a question about the television program 'EastEnders' during the general knowledge quiz; 2) to return an envelope with "MESSAGE" written on it when he/she was reminded that there were five minutes left in the test; and finally, 3) when the examiner informed him/her that the session was over, to remind the examiner to pick up five objects that had been hidden at the beginning of the session. Six points were awarded for each subtask that was successfully completed, unaided. If the task was completed after a single general prompt from the experimenter then 4 points were awarded. Alternatively participants were awarded two points if a second more specific prompt was required, one point if after prompting, the required action was completed on the second attempt and no point if the participant failed to complete the required action after prompting. Total scores were then generated on time-based and event based subscales, each scoring a maximum of 18 , with higher scores reflecting better prospective memory performance. The validity and reliability of the CAMPROMPT has been documented in a number of studies (i.e., Fleming et al., 2008; Groot et al., 2002; Wilson et al., 2005).

\section{Procedure}

Participants were informed of the purpose of the investigation and their right to withdraw at any time. After consent had been obtained the tests were administered under laboratory conditions. The drug-use questionnaire (Montgomery et al., 2005) was administered first followed by the Raven's progressive matrices (Raven et al., 1998), the age/education questionnaire, the PRMQ (Crawford et al., 2005), the MCQ (Dixon de Frias, \& Bäckman, 2001) and the BRIEF-A (Roth et al., 2005) questionnaires. Finally, the RAVLT and the CAMPROMPT (Wilson et al., 2005) tests were administered. Participants were fully debriefed, paid £20 in Tesco store vouchers and given drug education leaflets. The University of Central Lancashire's ethics committee approved the study. Data for the BRIEF-A obtained in the present study have been included with similar data that were collected previously by us from another group of participants and are the subject of a separate publication (Hadjiefthyvoulou et al., 2010). Participants also performed a range of other tasks that are beyond the scope of the present investigation.

\section{Results}


As is apparent from inspection of Table 1, with the exception of tobacco smoking the groups did not differ significantly on any of the background variables. The proportion of smokers differed significantly between the groups, $\chi 2(\mathrm{~N}=53, \mathrm{df}=2)=8.09, \mathrm{p}=.017$, however, the expected frequency in one of the cells, 3.94, was below the critical value of 5 thus although there are clear differences between the groups with $40-50 \%$ of illicit drug users regularly smoking and only 1 nonuser, the statistical significance of this is outcome is difficult to interpretcannot be confirmed by chi-squared. The daily consumption of cigarettes did not differ significantly between ecstasy/polydrug and cannabis only users, t (16) $=0.75$, $\mathrm{p}>.05$. Indicators of illicit drug use may be found in Table 2. It is clear that the ecstasy/polydrug group used a range of other illicit substances in addition to ecstasy, including cannabis, cocaine, and ketamine. Furthermore, for all of the measures of drug use, the median was substantially less than the mean, indeed in all cases the measures exhibited a positive skew, with a small minority of users demonstrating relatively high levels of use while the majority were clustered around the median. Members of both illicit drug using groups had also used poppers (amyl nitrate) during the preceding three months (as had one individual among the non illicit drug users). It is worthy of note that the various indicators of cannabis use did not differ significantly between the two illicit drug using groups.

Data screening revealed that there were no univariate outliers on the PM scores. However the distribution of the event-based PM measure deviated significantly from normal exhibiting a negative skew. Following the data transformation procedure recommended by Tabachnick and Fidell (2007) the event based scores were reflected and the square root was taken. This means that trends in the transformed variable are reversed so that higher scores are indicative of worse performance. Subsequent tests revealed that the distribution of the transformed variable did not deviate significantly from normal. Table 3 contains both the untransformed and the transformed event based PM measure. However the analyses reported below relate to the latter.

Inspection of Table 3 reveals that compared to the other two groups non illicit drug users displayed better PM performance on both the time and event based measures. The ecstasy/polydrug users' scores were the worst while cannabis only users' scores were between those of the other two groups. These trends were associated with statistically significant overall group differences. Subsequent post hoc tests revealed that with respect to the event-based PM measure, ecstasy/polydrug users performed significantly worse than the other two groups which in turn did not differ significantly from each other. The only statistically significant pairwise difference on the time-based PM measure was with respect to 
the ecstasy/polydrug group which performed significantly worse than the non illicit drug users group.

With regard to the BRIEF-A, the MCQ, and the RAVLT measures, two univariate outliers were identified, one on the decay score of the RAVLT and the other on the change score of the MCQ. These were replaced by the next highest/lowest score on the particular measure, plus/minus one (Tabachnick \& Fidell, 2007). On the basis of Mahalanobis distance no multivariate outliers were detected. Examination of Table 3 reveals that there were statistically significant group differences on only two of the non PM measures. First, the groups differed significantly on Crawford et al.’s (2005) self-report retrospective memory measure, with ecstasy/polydrug users scoring significantly worse than non illicit drug users (neither of the other pairwise comparisons were statistically significant). Second, non illicit drug users made significantly more use of external memory aids compared to ecstasy/polydrug users. The difference between the non users and cannabis-only users on the same measure approached significance.

For the sample as a whole, correlations between the PM and the other measures are set out in Table 4. The event based PM measure was significantly correlated with the time based measure (as might be expected). It was also significantly correlated with two of the retrospective memory measures: the Crawford et al. (2005) self-report measure and the recall score on the RAVLT over trials 1-5. Unsurprisingly, better retrospective memory performance was associated with better PM performance (High scores on the Crawford et al. measure are indicative of retrospective memory problems while the reverse is true of the time based and untransformed event based PM measures. Hence the correlation with the Crawford et al measure is negative in the former case and positive in relation to the transformed event based PM measure.) The correlation between the 'Reliance' subscale on the MCQ and the event based PM measure approached statistical significance: as reliance on others as an aid to memory increased, so PM performance decreased. Interestingly the event based PM measure was not significantly correlated with either of the BRIEF-A composite scales. The time based PM measure, like the event based, was significantly correlated with the Crawford et al. (2005) self-report retrospective memory measure, and with the recall score on the RAVLT over trials 1-5 the correlation approached significance; in both cases better retrospective memory was associated with better time-based PM performance. The correlation between the time based PM measure and the BRIEF-A metacognitive index also approached statistical significance. Higher executive functioning was associated with better time based PM performance. 
In order to evaluate the unique contributions of each of the predictors to PM performance, two regressions were run with respectively the transformed event based PM measure and the time based PM measure as dependent variables. Variables were included as predictors if they were significantly correlated (in bivariate terms) with the dependent variable or if they were associated with significant group differences on the dependent measure. In instances where the univariate or bivariate outcomes approached statistical significance, the variables in question were also included as predictors. The results for the regression analyses are set out in the penultimate two columns of Table 4. None of the individual predictors for time based PM were statistically significant, however, the overall model accounted for statistically significant variance $\left(\mathrm{r}^{2}=.285, \mathrm{p}<.05\right)$. The likely implication of this is that there was a degree of overlapping variance with pairs or larger combinations of predictors sharing pooled variance with the dependent variable making it impossible to allocate statistically significant unique variance to any one predictor. More specifically, it is possible that the statistically significant drug-related PM effects apparent in the ANOVA are in part mediated by drug-related differences on the other predictors, in particular, aspects of retrospective memory.

Switching the focus to event based PM, the regression model accounted for statistically significant variance, $\left(\mathrm{r}^{2}=.378, \mathrm{p}<.01\right)$. Of the individual predictors, the recall score on the RAVLT over trials 1-5 approached statistical significance, unsurprisingly better recall was associated with better PM performance. Of the other predictors, ecstasy/polydrug users (relative to other participants) accounted for statistically significant unique variance (reflecting the ecstasy/polydrug-related PM deficit). Thus it appears that the ecstasy/polydrug effect on event based PM cannot be entirely attributed to drug-related differences in retrospective memory and executive functioning. Surprisingly the dichotomous gender variable was also statistically significant as a predictor. Given the manner in which the variable was coded and the sign of the beta weight, this would suggest that females were performing worse than males on the event based PM task. Paradoxically, a subsequent $\mathrm{t}$ test revealed no statistically significant gender difference on the event based PM task, t (57) = $0.13, \mathrm{p}>.05$. However, further examination of the gender differences within the drug using groups showed that the gender deficit was only apparent among ecstasy/polydrug users. Among other participants, females were actually performing better. This raised the possibility of an interaction between gender and ecstasy/polydrug use in determining event based PM scores. In order to test this possibility the regression was repeated, this time, in addition to the ecstasy/polydrug and gender variables, their product was included as an independent variable 
in order establish whether or not there was a statistically significant interaction. The results are set out in the final column of Table 4, inspection of which reveals that in this expanded model only the interaction between gender and ecstasy/polydrug use accounts for statistically significant unique variance. Given the manner in which the dichotomous variables were coded, the positive beta coefficient indicates that female ecstasy/polydrug users were especially impaired on the event based CAMPROMPT task. By way of clarification subsequent analyses revealed that the mean scores for female ecstasy/polydrug users was $65 \%$ higher than that for female non ecstasy users, while the equivalent difference for males was just 16\% (as noted above higher scores are indicative of poorer event based PM performance).

The incidence of polydrug use among the ecstasy users makes it difficult to unambiguously attribute the impairments evident in PM to specific illicit drugs. In an attempt to address this issue Table 5 contains the simple and partial correlation coefficients between aspects of drug use on the one hand and the two PM measures on the other. Where an individual does not use a specific drug there usage has been coded as zero. Inspection of the Table reveals that only one aspect of drug use is correlated with time based PM, i.e., the current frequency of cannabis use. In view of this outcome no partial correlations were calculated for time based PM. By way of contrast, virtually all aspects of drug use were correlated with event based PM. However, when controls for the use of other illicit drugs were entered, aspects of ecstasy use were no longer significantly correlated with event based PM, rather it was aspects of cannabis and cocaine use which yielded statistically significant correlations.

The illicit drug users among our sample were requested to refrain from cannabis use for 24 hours prior to testing and from cocaine, ecstasy, and other drug use for 7 days prior to testing. In order to address the possibility that the PM differences that we observed were due to post intoxication effects we excluded all individuals who indicated that they had consumed ecstasy, cocaine, or cannabis during the 10 days prior to testing. This reduced the size of the cannabis-only group thereby reducing statistical power such that three-way group comparisons were not meaningful. For this reason the non illicit drug users and cannabis only users were merged to form a single group (drug naive/cannabis only $n=25$; ecstasy/polydrug $\mathrm{n}=14$ ). For the event based PM task the corresponding means (standard deviations) for the ecstasy/polydrug and combined drug naive/cannabis only users were respectively 2.20 (0.73) and 1.69 (0.47) which differenced significantly, $F(1,37)=7.10, \mathrm{p}<.05$. For the time based PM task the equivalent figures were respectively 10.92 (3.65) and 14.40 (4.65) which again 
differenced significantly, $F(1,37)=5.78, \mathrm{p}<.05$. Thus the ecstasy/polydrug related PM deficits remained statistically significant following removal of those persons who indicated that they had used illicit drugs during the previous 10 days.

\section{Discussion}

On the event based PM measure ecstasy/polydrug users were impaired relative to both cannabis only and non users of illicit drugs. This group was also impaired relative to nonusers on the time based measure. While a trend was evident on both measures with ecstasy/polydrug users performing worse, cannabis only users achieving intermediate levels of performance and non illicit drug users performing best, cannabis only users did not differ significantly from non users of illicit drugs on either PM measure. The ecstasy/polydrugrelated deficit observed here in relation to non illicit drug users is consistent with previous findings from our own and other laboratories using self report (Hadjiefthyvoulou et al., in press; Heffernan et al., 2001a; 2001b; Montgomery \& Fisk, 2007; Rodgers et al., 2001; 2003) and laboratory measures (Hadjiefthyvoulou et al., in press; Rendell et al., 2007a). They also demonstrate the utility of the CAMPROMPT measure in detecting individual differences in PM performance among non clinical populations augmenting the existing literature in this regard (Groot et al., 2002; Wilson et al., 2005).

For the most part ecstasy/polydrug deficits were not evident on the other measures that were administered. Deficits were only evident on the retrospective memory questionnaire and non users of illicit drugs were significantly more likely to report using external memory aids in everyday contexts. Cannabis-only users did not differ significantly from either of the other two groups on any of the non PM measures.

For the sample as a whole, individual differences on both PM measures were significantly correlated with outcomes on the retrospective memory questionnaire and with the RAVLT recall scores for the first five trials. In both cases better retrospective memory was associated with better PM performance. Scores on the BRIEF-A metacognitive index were also related to performance on the time based PM task with better executive functioning associated with improved PM performance, however, this trend only approached statistical significance two tailed (although given the directional nature of the anticipated effect, the outcome is statistically significant on a one-tailed basis). These findings are consistent with the outcomes reported above linking PM performance with medial temporal functioning (Adda et al., 2008; Martin et al., 2007) and with PFC processes (e.g., Okuda et al., 2007).

In order to establish the extent to which drug related deficits on the PM tasks were mediated by deficits in retrospective memory and executive functions, regressions were run 
with each of the PM variables as the criterion. For the time based PM task the dummy variable representing the effects of ecstasy/polydrug use was not statistically significant as a predictor. Indeed although the model as a whole accounted for statistically significant variance, none of the individual predictors were statistically significant. This suggests that any effects associated with ecstasy/polydrug use covary with individual differences in the other predictors and with the criterion leaving open the question of whether drug use per se adversely affects time based PM.

The regression analysis for event based PM yielded different results with only ecstasy/polydrug use and gender accounting for statistically significant unique variance. A further regression revealed that the two predictors in fact significantly interacted such that the ecstasy/polydrug related deficit was most pronounced amongst female users. Indeed neither of the main effects were statistically significant in the amended model. Of the other predictors in the model, the RAVLT recall scores for the first five trials approached statistical significance. It is noteworthy that the sum of the squared semi-partial correlation coefficients (.139) is far less than the overall R squared value (.431), indicating that most of the explained variance in the criterion reflects the overlapping effects of two or more predictors.

The emergence of gender specific illicit drug-related effects is not without precedent. For example, women who were heavy users of cannabis were impaired relative to female light users on visuo-spatial memory, while no such deficit emerged among male cannabis users (Pope et al., 1997). Gender was also found to moderate the extent of ecstasy-related deficits in design fluency (with female users exhibiting a deficit while male users actually performed better than controls) although it was not a moderating factor on deficits observed in verbal learning (Medina et al., 2005). Reneman et al. (2001) found that female ecstasy users exhibited a larger reduction in serotonin transporter densities relative to males. However, in a subsequent study in which ecstasy users were found to be impaired in various aspects of memory performance, female users were not significantly more affected than male users (Reneman et al., 2006). It is also worthy of note that the gender-drug use interaction only emerged on event based PM tasks and not on the time based PM measure. Thus the apparent gender difference observed in the present study should be treated with a degree of caution.

While deficits in aspects of PM are clearly evident among ecstasy/polydrug users, what is less clear is which illicit drug or drugs may be responsible for these deficits. It is striking that when the use of other drugs is controlled through partial correlation, no aspect of ecstasy use is statistically significant as a predictor of PM performance. It is also worthy of 
note that while cannabis-only users were not significantly impaired relative to non illicit drug users, they did performance worse on both PM measures compared with controls and cannabis use among the whole sample was significantly correlated with event based PM even following statistical controls for the effects of other illicit drugs. Higher levels of consumption during the previous 30 days and increasing frequency of use were associated with poorer event based PM performance. Thus the present results suggest that cannabis use does adversely affect PM performance although the effect may be accentuated among polydrug users. The present results augment those of other studies in which cannabis-related PM deficits have been observed, (e.g., Fisk \& Montgomery,2008; McHale \& Hunt, 2008; Rodgers et al., 2003).

A striking feature of the present results was that cocaine use was significantly correlated with event based PM performance even following statistical controls for the use of other illicit drugs. Increasing lifetime dose, greater consumption during the previous 30 days and an increased frequency of use are all associated with poorer event based PM performance. This replicates the results of our previous study (Hadjiefthyvoulou et al., in press), this time, with a different sample and with an alternative laboratory based PM measure. As far as we are aware, the present study and our previous one are the first to link the recreational use of cocaine with prospective memory deficits. The mechanisms through which cocaine might adversely affect PM functions remain unclear. On the basis of the results from their fMRI study, Tomasi et al. (2007) argue that a prior history of cocaine use disrupts the operation of those dopaminergic systems in the prefrontal cortex which underpin executive functioning. Given the key role of executive functions in supporting PM processes this might account for the adverse association between cocaine use and PM functioning.

It is also noteworthy that PM deficits have been observed in Parkinson's patients (Kliegel et al., 2005) and since the disease is characterised by disruption of dopaminergic functioning in the cortico-striatal pathway, this is consistent with a direct role for dopamine in supporting PM functions. Evidence consistent with this proposition emerged in a recent study by Costa et al (2008) in which administration of L-dopa significantly improved PM performance in a sample of Parkinson's patients relative to an unmedicated condition. As noted above, animal studies have also suggested a direct role for mesocortical dopaminergic systems in supporting prospective memory processes (Goto \& Grace, 2008). Since it is known that both cocaine and ecstasy potentially disrupt the functioning of dopaminergic systems, it is possible that the basis of the prospective memory deficits observed in the present study reside in impaired dopaminergic processes in the cortico-striatal pathway. 
A further possibility is that cocaine might give rise to impairment in medial temporal and hippocampal processes. In a recent study, Fox et al. (2009) found that performance on various aspects of the RAVLT was impaired among an inpatient cocaine dependent group. Relative to controls, deficits were related to self report stress levels and within the cocaine dependent group with raised early morning cortisol levels. Fox et al. attribute the stressrelated increase in cortisol levels and the associated memory deficits to hippocampal damage stemming from cocaine use. If this were the case, in the present context the recall component of PM performance might be compromised among recreational cocaine users thereby accounting for the results obtained here.

A number of limitations can be identified for this study. First, as with many studies in this area no objective measure of recent drug use such as urinalysis or hair analysis was used. Thus the period of abstinence cannot be objectively verified. Also, the purity of the ecstasy tablets or any other consumed drug cannot be guaranteed making it still more difficult to attribute the effects observed here to specific psychoactive drugs. Another important factor that should not be overlooked is that the apparent ecstasy/polydrug related deficits may not necessarily be a consequence of illicit drug use but instead be due to pre-existing differences between users and non users originating before the onset of illicit drug use. In addition, the possibility that current lifestyle differences or the effects of illicit drug use on other physiological processes (e.g., impaired sleep quality) might be the actual cause of the deficits observed in the current study cannot be entirely excluded. A methodological issue that needs to be considered is the relatively small sample size in the present study which means that the results of the regression analyses need to be treated with caution. Indeed, before definitive statements can be made regarding the relative importance of individual predictors, the regression analysis would need to be replicated with a substantially larger sample.

Nonetheless, the present results are potentially informative as a guide for which variables might be incorporated into future research utilising larger samples. Other methodological aspects of the present study might warrant a different approach in future research. For example, we used a self report measure of executive functioning rather than laboratory based measures. It might have been desirable to incorporate laboratory based tests of executive functioning, however, recent conceptualisations of executive functioning have emphasised the non unitary nature of these processes, identifying four or more separable processes: updating, inhibition, switching, and access to semantic memory (Fisk \& Sharp, 2004; Miyake et al, 2000) each with a number of specific measures. Furthermore, ecstasy/polydrug users appear to be differentially affected on each of these (Montgomery et al., 2005). Thus the 
inclusion of such a comprehensive test battery would have substantially expanded the length of the test session and was not possible given the resource constraints of the present study. Nonetheless future research might incorporate such measures, perhaps utilising latent variable analysis in order to evaluate the potential role of the various executive component processes with respect to a range of different PM measures.

To conclude, the present study intended to determine the impact of ecstasy/polydrug use and cannabis use on event based and time based prospective memory using the CAMPROMPT. Measures of executive functioning and retrospective memory were also administered in order to study the extent to which executive processes account for the prospective memory deficits in recreational drug users. Relative to both drug naive persons and cannabis only users, ecstasy/polydrug users performed significantly worse on both event based and time based prospective memory tasks while no significant differences in performance were observed between the cannabis user and non user groups. However, consistent with the results of our previous study, recreational use of cocaine was significantly correlated with event based prospective memory performance, demonstrating the need for a systematic investigation of the potential role of cocaine in accounting for the PM deficits that have been observed here and in other studies. 


\section{References}

Adda CC, Castro LHM, Além-Mar e Silva LC, de Manreza MLG, Kashiara R (2008). Prospective memory and mesial temporal epilepsy associated with hippocampal sclerosis. Neuropsychologia 46(7): 1954-1964.

Burgess PW, Scott SK, Frith CD (2003). The role of the rostral frontal cortex (area 10) in prospective memory: a lateral versus medial dissociation. Neuropsychologia 41: 906918.

Costa A, Peppe A, Brusa L, Caltagirone C, Gatto I, Carlesimo GA (2008) Dopaminergic modulation of prospective memory in Parkinson's disease. Behavioural Neurology 19: 45-48.

Crawford JR, Smith G, Maylor EA, Della-Sala S, Logie RH (2003). The prospective and retrospective memory questionnaire, (PRMQ): Normative data and latent structure in a large non-clinical sample. Memory 11: 261-275.

Dixon RA, de Frias CM, Bäckman L (2001). Characteristics of self-reported memory compensation in older adults. J Clin Exp Neuropsychol 23(5): 630-661.

Fisk JE, Montgomery C (2008). Real world memory and executive processes in cannabis users and nonusers. J Psychopharmacol 22: 727-736.

Fisk JE, Sharp CA (2004). Age-related impairment in executive functioning: Updating, inhibition, shifting, and access. J Clin Exp Neuropsychol 26: 874-890

Fleming J, Riley L, Gill H, Gullo MJ, Strong J, Shum D (2008). Predictors of prospective memory in adults with traumatic brain injury. J Int Neuropsychol Soc 14: 823-831.

Fox HC, Jackson ED, Sinha R (2009). Elevated cortisol and learning and memory deficits in cocaine dependent individuals: Relationship to relapse outcomes.

Psychoneuroendocrinology 34: 1198-1207.

Gilbert SJ, Frith CD, Burgess PW (2005). Involvement of rostral prefrontal cortex in selection between stimulus-oriented and stimulus-independent thought. Eur J Neurosci. 21: 1423-1431.

Goto Y, Grace AA (2008). Dopamine modulation of hippocampal-prefrontal cortical interaction drives memory-guided behavior. Cereb Cortex 18: 1407-1414.

Groot YCT, Wilson BA, Evans J, Watson P (2002). Prospective memory functioning in people with and without brain injury. J Int Neuropsychol Soc 8: 645-654. 
Hannon R, Adams P, Harrington S, Fries-Dias C, Gibson MT (1995). Effects of Brain injury and age on prospective memory self-rating and performance. Rehabil Psychol 40: 289-297.

Hadjiefthyvoulou F, Fisk JE, Montgomery C, Bridges N (2010). Self-reports of executive dysfunction in ecstasy/polydrug users. Manuscript submitted for publication.

Hadjiefthyvoulou F, Fisk JE, Montgomery C, Bridges N (in press). Everyday and prospective memory deficits in ecstasy/polydrug users. J Psychopharmacol.

Heffernan TM, Jarvis H, Rodgers J, Scholey AB, Ling J (2001a). Prospective memory, everyday cognitive failure and central executive function in recreational users of Ecstasy. Hum Psychopharmacol 16: 607-612.

Heffernan TM, Ling J, Scholey AB (2001b). Subjective ratings of prospective memory deficits in MDMA (“ecstasy”) users. Hum Psychopharmacol 16: 339-344.

Henry JD, Rendell PG, Kliegel M, Altgassen M (2007). Prospective memory in schizophrenia: Primary or secondary impairment? Schizophr Res 95(1-3): 179-185.

Kliegel M, Phillips LH, Lemke U, Kopp UA (2005). Planning and realisation of complex intentions in patients with Parkinson's disease. J Neurol Neurosurg Psychiatry 76: 1501-1505.

Leitz, JR, Morgan CJA, Bisby JA, Rendell PG, Curran HV (2009). Global impairment of prospective memory following acute alcohol. Psychopharmacology 205: 379-387.

Marsh RL, Hicks JL (1998). Event-based prospective memory and executive control of working memory. J Exp Psychol Learn Mem Cogn 24: 336-349.

Martin T, McDaniel MA, Houck JM, Woodruff CC, Bish JP, Moses SN, Kičić D, Tesche CD (2007). Brain regions and their dynamics in prospective memory retrieval: A MEG study. Int J Psychophysiol 64: 247-258.

McDaniel MA, Glisky EL, Guynn MJ, Routhieaux BC (1999). Prospective memory: A neuropsychological study. Neuropsychology 13: 103-110.

McHale S, Hunt N (2008). Executive function deficits in short-term abstinent cannabis users. Hum Psychopharmacol 23: 409-415.

Medina KL, Shear PK, Corcoran K (2005). Ecstasy (MDMA) exposure and neuropsychological functioning: A poly drug perspective. J Int Neuropsychol Soc 11: 753-765. 
Miyake A, Friedman NP, Emerson MJ, Witzki AH, Howerter A, Wager TD (2000) The unity and Diversity of executive functions, and their contributions to complex "frontal lobe” tasks: A latent variable analysis. Cognit Psychol 41: 49-100.

Montgomery C, Fisk JE (2007). Everyday memory deficits in ecstasy-polydrug users. J Psychopharmacol 21: 709-717.

Montgomery C, Fisk JE, Newcombe R (2005). The nature of ecstasy-group related deficits in associative learning. Psychopharmacology 180:141-149.

Montgomery C, Fisk JE, Newcombe R, \& Murphy PN (2005). The differential effects of ecstasy/polydrug use on executive components: Shifting, inhibition, updating and access to semantic memory. Psychopharmacology 182: 262-276.

Murphy PN, Wareing M, Fisk JE, Montgomery C (2009). Executive Working Memory Deficits in Ecstasy/MDMA Users: A Critical Review. Neuropsychobiology 60:159175.

Okuda J, Fujii T, Ohtake H, Tsukiura T, Yamadori A, Frith CD, Burgess PW (2007). Differential involvement of regions of rostral prefrontal cortex (Brodmann area 10) in time- and event-based prospective memory. Int J Psychophysiol 64: 233-246.

Paraskevaides T, Morgan CJA, Leitz JR, Bisby JA, Rendell PG, Curran HV (2010). Drinking and future thinking: Acute effects of alcohol on prospective memory and future simulation. Psychopharmacology 208: 301-308.

Pope HG Jr, Jacobs A, Mialet JP, Yurgelun-Todd D, Gruber S (1997). Evidence for a sexspecific residual effect of cannabis on visuospatial memory. Psychother Psychosom 66: 179-184.

Raven J, Raven JC, Court JH (1998). Manual for Raven’s Progressive Matrices and Vocabulary Scales. Oxford Psychologists Press, Oxford, UK

Rendell PG, Gray TJ, Henry JD, Tolan A (2007a). Prospective memory impairment in ecstasy (MDMA) users. Psychopharmacology 194: 497-504.

Rendell PG, Jensen F, Henry JD (2007b). Prospective memory in multiple sclerosis. J Int Neuropsychol Soc 13: 410-416.

Rendell PG, Mazur M, Henry JD (2009). Prospective memory impairment in former users of methamphetamine. Psychopharmacology 203: 609-616.

Reneman L, Booij J, de Bruin K, de Wolff FA, Gunning WB, den Heeten GJ, van den Brink W (2001). Effects of dose, sex, and long-term abstention from use on toxic effects of MDMA (ecstasy) on brain serotonin neurons. Lancet 358: 1864-1869. 
Reneman L, Schilt T, de Win MM, Booij J, Schmand B, van den Brink W, Bakker O (2006). Memory function and serotonin transporter promoter gene polymorphism in ecstasy (MDMA) users. J Psychopharmacol 20: 389-399.

Rey A (1964). L’examen clinique in psychologie. Press Universitaire de France, Paris Rodgers J, Buchanan T, Heffernan TM, Ling J, Parrott AC (2003). Patterns of drug use and the influence of gender on self-reports of memory ability in ecstasy users: A webbased study. J Psychopharmacol 17: 389-396.

Rodgers J, Buchanan T, Scholey AB, Heffernan TM, Ling J, Parrott A (2001). Differential effects of ecstasy and cannabis on self-reports of memory ability; a web based study. Hum Psychopharmacol Clin Exp 16: 619-625.

Roth RM, Isquith PK, Gioia GA (2005). Behavior Rating Inventory of Executive Function Adult Version. Psychological Assessment Resources, Inc, Odessa, Fla.

Solowij N, Hall W, Lee N (1992). Recreational MDMA use in Sydney: a profile of ecstasy users and their experiences with the drug. Br J Addict 87: 1161-1172.

Spooner DM, Pachana NA (2006). Ecological validity in neuropsychological assessment: A case for greater consideration in research with neurologically intact populations. Arch Clin Neuropsychol 21: 327-337.

Tabachnick BG, Fidell LS (2007). Using Multivariate Statistics, $\left(5^{\text {th }}\right.$ Ed.). Allyn and Bacon, Boston, MA, USA

Thompson C, Henry JD, Rendell PG, Withall A, Brodaty H (2010). Prospective memory function in mild cognitive impairment and early dementia. J Int Neuropsychol Soc 16: 318-325.

Tomasi D, Goldstein RZ, Telang F, Alia-Klein N, Volkow ND, Caparelli EC, Maloney T (2007). Widespread disruption in brain activation patterns to a working memory task during cocaine abstinence. Brain Res 1171: 83-92.

Wilson BA, Clare L, Baddeley AD, Cockburn J, Watson P, Tate R (1999). The Rivermead Behavioural Memory Test- Extended Version (RBMT-E). Thames Valley Test Company, Bury St Edmunds

Wilson BA, Emslie H, Foley J, Shiel A, Watson P, Hawkins K, Groot Y, Evans JJ (2005). The Cambridge Prospective Memory Test (CAMPROMPT). Harcourt Assessment, London 
Table 1 Age, intelligence, years of education, cigarette and alcohol use by group.

\begin{tabular}{|c|c|c|c|c|c|c|c|c|c|c|}
\hline & \multicolumn{3}{|c|}{$\begin{array}{l}\text { Ecstasy/Polydrug } \\
\text { Users }\end{array}$} & \multicolumn{3}{|c|}{ Cannabis-Only Users } & \multicolumn{3}{|c|}{ Nonusers } & \multirow[t]{2}{*}{$\mathrm{p}^{1}$} \\
\hline & Mean & S.D. & $\mathrm{n}$ & Mean & S.D. & $\mathrm{n}$ & Mean & S.D. & $\mathrm{n}$ & \\
\hline Age (years) & 21.17 & 1.79 & 29 & 21.92 & 1.56 & 12 & 20.44 & 2.28 & 18 & ns \\
\hline $\begin{array}{l}\text { Ravens Progressive } \\
\text { Matrices (maximum 60) }\end{array}$ & 39.21 & 8.39 & 29 & 40.25 & 7.35 & 12 & 40.72 & 8.90 & 18 & ns \\
\hline Years of Education & 15.27 & 2.44 & 26 & 14.92 & 4.06 & 12 & 16.00 & 2.00 & 18 & ns \\
\hline Cigarettes per day & 7.42 & 4.48 & 12 & 9.00 & 3.58 & 6 & 15.00 & - & 1 & .017 \\
\hline $\begin{array}{l}\text { Alcohol (Units per } \\
\text { week) }\end{array}$ & 13.41 & 12.08 & 27 & 15.18 & 12.95 & 11 & 9.47 & 14.70 & 15 & ns \\
\hline
\end{tabular}

1. For one-way ANOVA except cigarettes where $\chi^{2}$ test was used. 
Table 2. Indicators of Illicit Drug Use

\begin{tabular}{|c|c|c|c|c|c|c|c|c|c|}
\hline & \multicolumn{4}{|c|}{ Ecstasy/Polydrug Users } & \multicolumn{4}{|c|}{ Cannabis-Only Users } & \multirow[t]{2}{*}{$\mathrm{p}^{1}$} \\
\hline & Median & Mean & S.D. & $\mathrm{n}$ & Median & Mean & S.D. & $\mathrm{n}$ & \\
\hline \multicolumn{10}{|l|}{ Total Use } \\
\hline Ecstasy (Tablets) & 194 & 640.86 & 1284.99 & 29 & - & - & - & - & - \\
\hline Cannabis (joints) & 728 & 3048.84 & 5297.53 & 25 & 1118 & 2242.58 & 3307.71 & 12 & ns \\
\hline Cocaine (lines) & 416 & 1037.89 & 1282.60 & 19 & & - & - & - & - \\
\hline \multicolumn{10}{|l|}{$\begin{array}{l}\text { Amount Consumed } \\
\text { in Previous } 30 \text { Days }\end{array}$} \\
\hline Ecstasy (Tablets) & 0 & 3.14 & 8.28 & 29 & - & - & - & - & - \\
\hline Cannabis (joints) & 1 & 26.08 & 45.80 & 25 & 0.50 & 22.25 & 33.05 & 12 & ns \\
\hline Cocaine (lines) & 2 & 8.16 & 12.74 & 19 & - & - & - & - & - \\
\hline \multicolumn{10}{|l|}{$\begin{array}{l}\text { Frequency of Use } \\
\text { (times per week) }\end{array}$} \\
\hline Ecstasy & 0.04 & 0.24 & 0.43 & 29 & - & - & - & - & - \\
\hline Cannabis & 0.25 & 1.87 & 2.52 & 25 & 0.15 & 1.86 & 2.71 & 12 & ns \\
\hline Cocaine & 0.06 & 0.28 & 0.36 & 19 & - & - & - & - & - \\
\hline \multicolumn{10}{|l|}{$\begin{array}{l}\text { Weeks Since Last } \\
\text { Use: }\end{array}$} \\
\hline Ecstasy & 12 & 47.00 & 76.32 & 29 & - & - & - & - & - \\
\hline Cannabis & 4 & 20.34 & 37.13 & 25 & 7.50 & 73.32 & 113.69 & 12 & ns \\
\hline Cocaine & 6 & 15.40 & 24.36 & 22 & - & - & - & - & - \\
\hline $\begin{array}{l}\text { Use of Other Drugs } \\
\text { during the Previous } \\
3 \text { Months }\end{array}$ & Percent & & & & Percent & & & & \\
\hline Amphetamine & 3 & & & & 0 & & & & \\
\hline Ketamine & 31 & & & & 8 & & & & \\
\hline LSD & 3 & & & & 0 & & & & \\
\hline Magic Mushrooms & 3 & & & & 0 & & & & \\
\hline Poppers & 45 & & & & 17 & & & & \\
\hline
\end{tabular}

1. For Mann-Whitney U 
Table 3. Outcomes for the Prospective Memory, Executive Functions, and Memory Measures by Group.

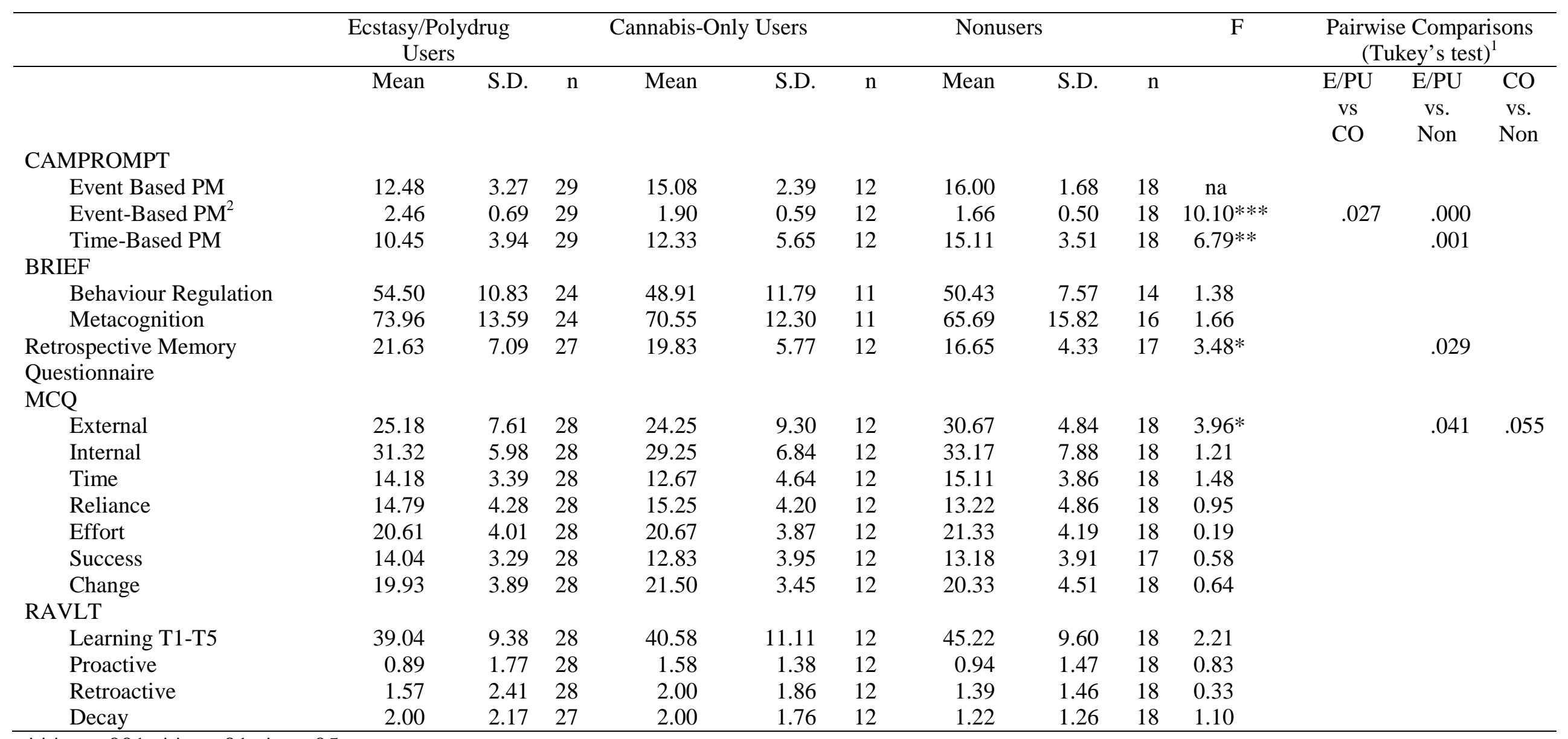
$* * *, \mathrm{p}<.001 ; * * \mathrm{p}<.01 ; * \mathrm{p}<.05$

1. Only statistically significant differences or differences approaching statistical significance are reported.

2. This is the transformed variable where higher scores are indicative of worse performance. 
Table 4

The Relationship between Time and Event Based PM and Executive and Memory Functions

\begin{tabular}{|c|c|c|c|c|c|}
\hline \multirow[t]{2}{*}{ Correlate/IV } & \multicolumn{2}{|c|}{ Simple Correlation } & \multicolumn{3}{|c|}{$\begin{array}{l}\text { Standardised beta weight and (squared semi- } \\
\text { partial correlation from regression) }\end{array}$} \\
\hline & $\begin{array}{r}\text { Event- } \\
\text { Based } \\
\text { PM }^{1}\end{array}$ & $\begin{array}{r}\text { Time- } \\
\text { Based PM }\end{array}$ & $\begin{array}{l}\text { DV = Event- } \\
\text { Based PM }{ }^{1}\end{array}$ & $\begin{array}{l}\text { DV = Time- } \\
\text { Based PM }\end{array}$ & $\begin{array}{l}\text { DV }=\text { Event- } \\
\text { Based PM }\end{array}$ \\
\hline \multicolumn{6}{|l|}{ CAMPROMPT } \\
\hline Event-Based $\mathrm{PM}^{1}$ & & $-.523 * * *$ & & & \\
\hline Time-Based PM & $-.523 * * *$ & & & & \\
\hline \multicolumn{6}{|l|}{ BRIEF } \\
\hline Behaviour Regulation & .184 & -.105 & & & \\
\hline Metacognition & .130 & $-.248^{\dagger}$ & & $.034(.001)$ & \\
\hline Retrospective Memory & $.270 *$ & $-.381 * *$ & $.019(.000)$ & $-.361(.038)$ & $-.026(.000)$ \\
\hline \multicolumn{6}{|l|}{ Questionnaire } \\
\hline \multicolumn{6}{|l|}{ MCQ } \\
\hline External & -.075 & .052 & $-.172(.014)$ & $.097(.003)$ & $-.154(.012)$ \\
\hline Internal & -.003 & .007 & & & \\
\hline Time & -.084 & -.068 & & & \\
\hline Reliance & $.258^{\dagger}$ & -.184 & $.180(.021)$ & & $.194(.024)$ \\
\hline Effort & -.193 & -.064 & & & \\
\hline Success & .019 & .008 & & & \\
\hline Change & .035 & -.021 & & & \\
\hline \multicolumn{6}{|l|}{ RAVLT } \\
\hline Learning T1-T5 & $-.273^{*}$ & $.244^{\dagger}$ & $-.239(.051)^{\dagger}$ & $.217(.040)$ & $-.208(.038)$ \\
\hline Proactive & .008 & -.042 & & & \\
\hline Retroactive & .095 & .033 & & & \\
\hline Decay & .152 & -.060 & & & \\
\hline Gender & & & $.314(.060)^{*}$ & $-.090(.004)$ & $.012(.000)$ \\
\hline $\begin{array}{l}\text { Ecstasy/polydrug versus all } \\
\text { others }\end{array}$ & & & $.555(.138)^{* *}$ & $-.277(.034)$ & $.218(.011)$ \\
\hline $\begin{array}{l}\text { Ecstasy/polydrug versus all } \\
\text { others by Gender interaction }\end{array}$ & & & - & - & $.423(.053)^{*}$ \\
\hline \multirow{3}{*}{$\begin{array}{l}\text { Cannabis-only versus all } \\
\text { others }\end{array}$} & & & $.095(.005)$ & $-.130(.009)$ & $.037(.001)$ \\
\hline & & & $r^{2}=.378$ & $r^{2}=.285$ & $r^{2}=.431$ \\
\hline & & & $\begin{array}{r}\mathrm{F}(7,47)=4.09 \\
\mathrm{p}<.01\end{array}$ & $\begin{array}{r}\mathrm{F}(7,41)=2.34, \\
\mathrm{p}<.05\end{array}$ & $\begin{array}{r}F(8,46)=4.36 \\
p<.001\end{array}$ \\
\hline
\end{tabular}

$* * *, \mathrm{p}<.001 ; * * \mathrm{p}<.01 ; * \mathrm{p}<.05 ;{ }^{\dagger} \mathrm{p}<.10$.

1. This is the transformed variable where higher scores are indicative of worse performance. 
Table 5

The Relationship between Time and Event Based PM and Indicators of Illicit Drug Use

\begin{tabular}{llll}
\hline & \multicolumn{2}{c}{$\begin{array}{c}\text { Event- } \\
\text { Based PM }\end{array}$} & \multicolumn{1}{c}{$\begin{array}{c}\text { Time } \\
\text { Based PM }\end{array}$} \\
\hline & $\begin{array}{l}\text { Simple } \\
\text { Correlation }\end{array}$ & $\begin{array}{l}\text { Partial } \\
\text { Correlation }\end{array}$ & $\begin{array}{l}\text { Simple } \\
\text { Correlation }\end{array}$ \\
Cannabis & $.246^{*}$ & .208 & -.154 \\
$\quad$ Total Lifetime Use & $.259^{*}$ & $.230^{*}$ & -.158 \\
$\quad$ Consumed in last 30 days & $.338^{* *}$ & $.390^{* *}$ & $-.286^{*}$ \\
$\quad$ Frequency & & & \\
& & & \\
Cocaine & $.339^{* *}$ & $.328^{* *}$ & -.139 \\
$\quad$ Total Lifetime Use & $.257^{*}$ & $.261^{*}$ & -.126 \\
$\quad$ Consumed in last 30 days & $.403^{* *}$ & $.416^{* * *}$ & -.133 \\
$\quad$ Frequency & & & \\
& & & -.160 \\
Ecstasy & $.261^{*}$ & -.002 & -.058 \\
$\quad$ Total Lifetime Use & .210 & -.036 & -.065 \\
Consumed in last 30 days & $.268^{*}$ & -.028 & \\
Frequency & & &
\end{tabular}

***, $\mathrm{p}<.001 ; * * \mathrm{p}<.01 ;{ }^{*} \mathrm{p}<.05$; one tailed.

1. Correlation for the transformed variable.

2. Controlling for the use of other drugs on the measure in question, e.g., the correlation between total use of cannabis and PM controlling for the total use of cocaine and total use of ecstasy. 